\title{
SOĞUK SAVAŞ SONRASI KOSOVA SORUNU (1989-2000)
}

\author{
3. Bask1
}

Prof. Dr. Hüseyin EMiRoĞLU 


\section{(C) Copyright 2021}

Bu kitabın, basım, yayın ve satış hakları Akademisyen Kitabevi A.Ş.'ne aittir. Anılan kuruluşun izni alınmadan kitabın tümü ya da bölümleri mekanik, elektronik, fotokopi, manyetik kağıt ve/veya başka yöntemlerle çoğaltılamaz, basılamaz, dağıtılamaz. Tablo, şekil ve grafikler izin alınmadan, ticari amaçlı kullanılamaz. Bu kitap T.C. Kültür Bakanlı̆̆ bandrolü ile satılmaktadır.

\section{ISBN}

978-625-7354-30-1

\section{Kitap Adı}

Soğuk Savaş Sonrası Kosova Sorunu (1989-2000)

\section{Yazar}

Prof. Dr. Hüseyin EMİROĞLU

Yayın Koordinatörü

Yasin Dilmen

Sayfa ve Kapak Tasarımı

Akademisyen Dizgi Ünitesi

Yayıncı Sertifika No

47518

Baskı ve Cilt

Vadi Matbaacılık

Bisac Code

HIS037070

DOI

10.37609/akya.812

\section{GENEL DAĞITIM Akademisyen Kitabevi A.Ş.}

Halk Sokak 5 / A

Yenişehir / Ankara

Tel: o312 4311633

siparis@akademisyen.com 


\section{Ön Söz}

Balkan yarımadası, coğrafi açıdan çok önemli bir geçiş bölgesi olması ve güçlü deniz bağlantısı nedeniyle, Avrasya eksenli tüm büyük siyasal güç merkezleri tarafından hâkimiyet altına alınma mücadelesine tanık olunan bir bölgedir. Bölgeyi hâkimiyeti altında tutan merkezi imparatorlukların zayıflaması ve dağılması süreci, merkezkaç siyasal yapılar arasında çok çatışmacı ilişkilerin başlamasına yol açmaktadır. Bu süreç sonucunda çoğu zaman merkezkaç siyasal yapılardan bir tanesi, benzer siyasal hedefler taşıan diğer merkezkaç unsurları hâkimiyeti altına alarak merkezi inşa etmektedir. Bu dönem, uluslararası politik ilişkilerde çatışma dinamiğinin çok yüksek olduğu bir safhanın geride kalması anlamına gelmektedir. Bölgede büyük bir merkezi siyasal yapının inşası sonucu, (Balkanlar eksenli) uluslararası politik ilişkilerde istikrarlı bir döneme girilmektedir. Ancak bu süreçler boyunca merkez-merkezkaç güçler arasında sürmekte olan güç mücadelesi ekseninde yaşanan olaylar halkların tarihsel belleğinde çok derin izler bırakmaktadır. Dünya siyasal sisteminde yaşanan çok köklü dönemsel değişim ve dönüşümler, uluslararası politika alanında çatışmacı dinamikleri gün yüzüne çıkarabilmektedir. Halkların tarihsel belleğindeki negatif imajlar, çatışmacı uluslararası politika ortamını besleyecek çok güçlü argümanlar sunabilmektedir.

Soğuk Savaş sonrası Balkanlar bölgesi, uluslararası politikanın gündemini 11 yll boyunca (1989-2000) yaşanan şiddet ve savaş olayları/gelişmeleri ile meşgul etmiştir. Yugoslavyảnın dağılması süreci, bir yandan federatif yapıdan bağımsızlığını ilan eden cumhuriyetler, diğer yandan Kosova gibi özerk bölgelerin bağımsızlık isteğini öne çıkartmıştır. Sırbistan siyasal seçkinlerinin, ülkelerini merkeze alarak inşa etmeye çalıştıkları yeni siyasal yapının kurgulanması ve gerçekleştirilmesi için üretilen dış politika yönelimleri ise askeri kuvvet kullanımını önceleyen bir nitelik taşımaktadır. Bu tarz bir dış politika yöneliminin, Balkanlar eksenli uluslararası politika ilişkilerinde çatışma dinamiğini arttıracağı, bölgesel ve küresel dengeleri derinlemesine sarsacağı açıktır. 
$\mathrm{Bu}$ çalışma, bölgesel ve küresel dengeleri etkileme noktasında Balkanlar bölgesinin 'yayılma' potansiyeli en büyük sorunu olarak nitelenebilecek 'Kosova Sorunu'nu; sorunun uluslararası politikada çatışma dinamiğini arttırmasının tarihsel ve dönemsel sebeplerini derinlemesine inceleyen çözümlemeci bir çabanın ürünüdür. Soğuk Savaş sonrası Yugoslavyảnın dağılması süreciyle ilgili çok sayıda akademik çalışma yapılmıştır. Elinizdeki çalışma, belki biraz iddialı bir ifade olabilir ancak Soğuk Savaş sonrası Balkan yarımadası eksenli yaşanan çatışmaların kökenine dair oldukça kapsamlı bir uluslararası politika çözümlemesidir. Bu noktada Balkan çalışmaları konusunda önemli bir boşluğu dolduracağını düşünüyorum. Bu alandaki akademik çalışmaların artması sürecine kendi ölçeğinde bir katkı sağlaması yazar açısından ayrıca sevindirici bir husustur.

$\mathrm{Bu}$ çalışmanın hazırlanmasına, Kırıkkale Üniversitesi Uluslararası İlişkiler Bölümünde 2001 yılından bu yana vermekte olduğum Uluslararası İlişkilerde Balkanlar Dersi çerçevesinde yürüttüğüm çalışmaların çok büyük katkısı olmuştur. Bunun dışında bu tarz bir çalışmanın ortaya konulması çok uzun ve sabırlı bir çalışma sürecini içermektedir. Bu noktada lisans eğitimim süresince ve sonrasında her konuda yardımlarını arkamda hissettiğim sevgili anne ve babama; lisans eğitiminin sonunda bizleri akademik çalışma alanına yönlendiren değerli hocam Prof. Dr. Tayyar Arı'ya; İstanbul Üniversitesindeki yüksek lisans ve doktora çalışmaları esnasında gerek akademik bilgi birikimimin artmasında ve gerekse çalışmalarımı yürütmekte çok büyük katkılarını gördüğüm Prof. Dr. Faruk Sönmezoğlu ve Prof. Dr. Toktamış Ateş’e teşekkürü bir borç bilirim. Bu çalışmamın hazırlığını yürüttüğüm beş yıl boyunca, her türlü yardım ve desteğini arkamda hissettiğim eşime, çalışmalarım esnasında beni rahatsız etmemeye çalışan çocuklarıma da minnettarlığımı ve teşekkürlerimi sunuyorum. Tabii ki çalışmanın bütün eksik ve kusurları şahsıma aittir. 


\section{Kisaltmalar}

$\mathrm{AB}:$

Avrupa Birliği

ABD: $\quad$ Amerika Birleşik Devletleri

AGİT: $\quad$ Avrupa Güvenlik ve İşbirliği Teşkilatı

AGIT KIM: $\quad$ Avrupa Güvenlik ve İşbirliği Teşkilatı Kosova İnceleme Komisyonu

BK: $\quad$ Bali Kombetar

bkz:: $\quad$ Bakınız

BM: $\quad$ Birleşmiş Milletler

CIA: $\quad$ Central Intelligence Agency/Merkezi İstihbarat Ajans1

COM-KFOR: Commander Kosovo Force/Kosova Kuvveti Komutanı

DB: $\quad$ World Bank/Dünya Bankası

fk.: $\quad$ Fikra

FRY: $\quad$ Former Republic of Yugoslavia/Eski Yugoslav Cumhuriyeti

GDH/OTPOR: Gençlik Direniş Hareketi

IMF: International Monetary Fund/Uluslararası Para Fonu

IMRO: $\quad$ Devrimci Makedonyalılar Örgütü

JIC: $\quad$ Joint Implementation Commission/Ortak Tamamlama Komisyonu

KDL/UÇK: Kosovo Liberation Army/Kosova Kurtuluş Ordusu

KDİ/KDL: $\quad$ Kosova Demokratik İttifaki/Kosova Demokratik Ligi

KFOR: $\quad$ Kosovo Force/Kosovo Kuvveti

KGK: $\quad$ Kosovo Geçici Konseyi

KYDL: Kosovảnın Yeni Demokratik Ligi

MC: $\quad$ Milletler Cemiyeti

md.: $\quad$ Madde

NATO: $\quad$ North Atlantic Treaty Organization

NGO: $\quad$ Non-Governmental Organization/Hükümetdışı Örgütler 
PROFOR: $\quad$ Protection Force/Koruma Kuvveti

SFOR: $\quad$ Stabilization Force

SKO/WASP: $\quad$ Sirp Kurtuluş Ordusu

SRS/SRP: $\quad$ Serbian Radical Party/Sirp Radikal Partisi

SRT: $\quad$ Sirp Radyo-Televizyonu

TBMM: $\quad$ Türkiye Büyük Millet Meclisi

UAD: $\quad$ Uluslararası Adalet Divanı

UADS: $\quad$ Uluslararası Adalet Divanı Statüsü

UKH: $\quad$ Ulusal Kurtuluş Hareketi

UN: $\quad$ United Nations

UNHCR: United Nations High Commissioner for Refugees

UNICEF: United Nations International Children's Fund

UNMIK: $\quad$ United Nations Mission in Kosovo

YD: $\quad$ Yeni Demokrasi

İHİÖ/HRW: İnsan Hakları İzleme örgütü/Human Rights Watch 


\section{IÇiNDEKILER}

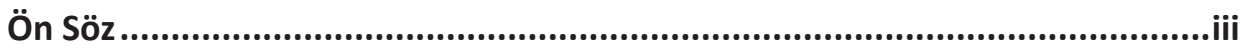

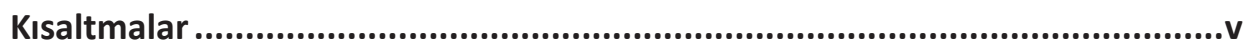

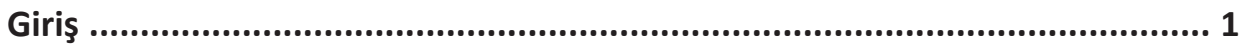

Tarihsel Süreç Boyunca Kosova (Sorunu) ve Teorik Bir Yaklaşım .......... 5

Kosova Sorununun Tarihsel Arkaplanına Teorik Bir Yaklaşım:

İbn Haldun'un Mülk Teorisi ...................................................................... 7

İbn Haldun'un Mülk Teorisi Çerçevesinde Balkan Yarımadasında Yaşanan

Merkezileşme ve Güç Mücadelesi .............................................................. 18

Tarihsel Süreç İçerisinde Kosova'nın Coğrafi - Demografik - İdari Yapısı....... 51

\section{Soğuk Savaş Sonrası Dönemde Kosova Bölgesinin Uluslararası Barış} ve Güvenliğe Yönelik Tehdit İçeren Bir Soruna Dönüşmesi Süreci ....... 79

Tarihsel Dinamikleriyle Birlikte Soğuk Savaş Sonrası Kosova Sorunu............. 79

$A B$ ve $A B D$ 'nin Kosova Sorunu Karşısındaki Tutum ve Yaklaşımları................ 93

Kosova Sorunu Karşııında Bölgesel Güçlerin Tutum ve Yaklaşımları ........... 101

Bağlant Grubu'nun Kosova Sorununun Çözümüne Yönelik Çabaları .......... 109

Belgrad Yönetiminin ve Kosovalı Arnavutların Kosova Sorununa Yönelik

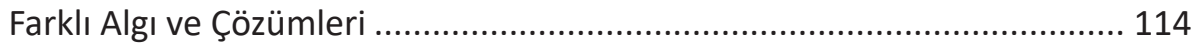

Kosova Bölgesinde Ilımlı Liderlik Kavramının Aşınması ve Şiddetin

Toplumsallaşması Süreci...................................................................... 117

Kosova'da Karşılıklı Tırmanan Şiddet ve Uluslararası Toplumun Artan Ilgisi.. 121 
Sırbistan'ın Kosovalı Arnavutlara Yönelik Askeri Kuvvet Kullanımı ve Kosova Kurtuluş Ordusu'nun (UÇK) Kosova Sorununun Temel Aktörlerinden Biri Olarak Tanınması

Sırbistan'ın Kosova Bölgesine Yönelik Stratejik Hesapları Çerçevesinde Uyguladığı Şiddet ve Uluslararası Toplumun Tepkisi.

Uluslararası Toplumun Kosova Sorunu Karşısında Farklı Tutum-Yaklaşımları, Nedenleri ve Taraflara Etkisi

Uluslararası Toplumdaki Farklı Tutum - Yaklaşımların Sonuçları....

Kosova Sorununun Çözümüne Yönelik Artan Diplomasi Trafiği ve Taraflarca

Atılan Stratejik Adımlar/Sorunlar 146

Sırbistan Yönetiminin Kosova Sorununa Yönelik Geliştirmeye Çalıştiğı

Diplomasi/Şiddet Eksenli Strateji ve Yolaçtı̆̆ Sonuçlar.....

Sırbistan'ın Şiddet Eksenli Politikasına Uluslararası Toplumun Tepkisi ve Meydana Gelen Gelişmeler.

Kosova Sorununa Müzakereler Yoluyla Çözüm Arayışı: Birinci Tur Rambouilet Müzakereleri ve Çözümsüzlük ....................................................... 161

İkinci Tur Rambouillet Müzakereleri ve Rambouillet Anlaşması................. 168

\section{Uluslararası Toplumun Kosova Sorunu Karşısında Ortaya Koyduğu Yaklaşım ve Davranışlar}

Uluslararası Toplumun Kosova Sorununun Çözümüne Yönelik Öne Çıkardığı

Dış Politika Aracı: Askeri Kuvvet Kullanımı.

NATO’nun Yugoslavya'ya Karşı Askeri Kuvvet Kullanımına Yönelik Tepkiler. 180

NATO Hava Kampanyasının Yöneldiği Hedefler ve Stratejik Amaçlar.

NATO Hava Kampanyasının Miloseviç Yönetimine Sunduğu Tarihsel

Fırsatlar ve Yolaçması Olası Sonuçlar.

$A B D$ ve $A B$ Ülkelerinin NATO Hava Kampanyasının Sürdürülmesine

Yönelik Kararlı Tutumları ve Tepkiler

NATO Hava Kampanyası Süresince Yaşanan Aksaklıklar .......................... 190

NATO Hava Kampanyasının İlk Aşamasında Sağlanan Başarılar ................ 193

NATO Hava Kampanyasının IIlk Aşamasında Kosova'da UÇK'nın Faliyetleri ... 195



NATO Hava Kampanyasının İlk Aşamasında Yaşanan Diplomatik Gelişmeler .. 197 
NATO Zirvesi-Kara Askerlerinin Kullanımı Konusunda Tartş̧ma -

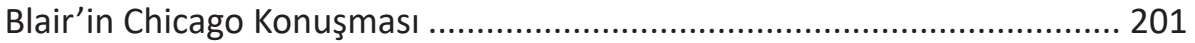

Yugoslavya Üzerine Avrupa Birliği Petrol Ambargosu.................................. 204

NATO Hava Kampanyasının IIlk Aşamasında Mültecilerin Durumu .............. 206

Kaçan Arnavutlar Tarafindan Saldırılara/Vahşete Dair Açıklamalar ............ 212

NATO Hava Kampanyasının Karadağ İç Siyasal Sisteminde Yol Açtığı

Gelişmeler

NATO Hava Kampanyasının Yugoslavya'nın İç Siyasal Sisteminde Yol

Açtğ̆ Gelişmeler

Mayıs 1999 Boyunca Yugoslavya'ya Karşı Devam Eden NATO Hava

Saldırıları Sürecinde Meydana Gelen Gelişmeler ve NATO Hava

Kampanyasındaki Sorunlar .................................................................... 217

Çin Büyükelçiliği'ne NATO Saldırısı ve Tepkiler ........................................... 221

Çin Büyükelçiliği'ne Yönelik Füze Saldırısına Yönelik Tepkilere Karşın NATO Hava Saldırılarının Sürdürülmesindeki Kararlılık ve Etkileri ......................... 225

Sırbistan'da Savaş Karşıtt Gösterilere Ait Raporlar..................................... 227

NATO Saldırılarının Sürdüğü Mayıs 1999 İtibariyle UÇK'nın Faaliyetleri..... 228

ABD Askerlerinin Serbest Bırakılması ....................................................... 229

Bulgaristan'ın NATO’nun Hava Sahasını Kullanmasını Onaylaması .............. 230

Mayıs 1999 İçerisinde Meydana Gelen Diplomatik Gelişmeler .................. 230

Savaş Suçları Konusunda Milosevic'in Suçlanması ..................................... 240

NATO Hava Kampanyasının İkinci Ayında Mültecilerin Durumu .................. 242

\section{Kosova Sorununun Çözümüne Doğru: Askeri Kuvvet Kullanımından} Siyasi Müzakerelere...............................................................245

Yugoslavya Kuvvetlerinin Kosova'dan Geri Çekilmesi ve NATO Hava Kampanyasının Sona Erdirilmesi ............................................. 245

Yugoslavya'nın Barış Planını Kabulü........................................................... 246

Yugoslavya ve NATO Arasında Askeri Teknik Anlaşması'nın İmzalanması... 250 Yugoslavya ve NATO Arasında İmzalanan Askeri Teknik Anlaşması'nın

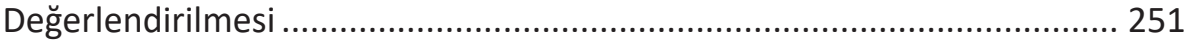

Birleşmiş Milletler (BM) Güvenlik Konseyi Kararı ....................................... 252 
Yugoslavya Devlet Başkanı Slobodan Milosevic'in 10 Haziran 1999

Tarihinde Yapmış Olduğu Ulusa Sesleniş Konuşmasının Değerlendirilmesi . 258

Rusların Kosova'ya Girişleri ve Yol Açthğı Sorunlar, KFOR Askerlerinin

Konuşlandırılması ve Yugoslavya Kuvvetlerinin Geri Çekilmesi .................. 263

Kosova'dan Sırpların Kaçışı ve Etnik Arnavut Mülteciler’in Geri Dönüşü.... 267

NATO’nun UÇK'nın Silahtan Arındırılması ve Dönüştürülmesi Sorumluluğu ...270

UÇK Tarafindan Silahsızlanma ve Silahtan Arındırmanın Üstlenilmesi Anlaşmasının Değerlendirilmesi ...................................................... 272

Savaş Suçlarının Soruşturulması ..................................................... 274

NATO’nun Kosova Sorunu Çerçevesinde Çatş̧mada Gelinen Noktayı

Değerlendirmesi.....

Uluslararası Savaş Suçları Mahkemesi’ne Yugoslavya'nın Yaptı̆̆

Başvurunun Reddedilmesi

14 Haziran 1999 Sonrasında Yugoslavya'da Yaşanan İç

Siyasal Gelişmeler. 278

Yugoslavya'nın İç Siyasal Sisteminde Yaşanan Gelişmeler ........................ 280

Kosova'da BM Geçici Yönetim Misyonunun (UNMIK) Yapılandırılması....... 280

Kosova Geçici Konseyi'nin Toplanması-Etnik Arnavut Toplum İçindeki

Bölünmeler.

Yugoslav Askerlerinin Kosova'yı Tahliye Etmesi Sonrasında Mültecilerin

Durumu ve Uğradıkları Zararların Değerlendirilmesi..

Yugoslavya Askerlerinin Tahliyesinden Sonra Sırplara

Yönelik Şiddet Eylemleri

Kosova'nın Rehabilitasyonu İçin Düzenlenen Bağış Konferansı ................. 289

Kosova Sorununu Ele Almak Üzere Düzenlenen Balkan Zirvesi ................. 290

Sırbistan'da Milosevic Karşıt Gösterilerin Yaygınlaşması ......................... 293

NATO Hava Kampanyası'nın Sona Erdirilmesinden Sonra Yaşanan

Gelişmeler ve BM Barış Koruma Kuvveti'nin Faaliyetleri.......................... 295

İbrahim Rugova'nın Kosova Geçici Konseyi ile İşbirliği Yapması ................. 299

Yugoslavya'nın İç Siyasal Atmosferinde Milosevic'e Karşı Süren Muhalefet ve Sonuçları.

Kosova Barışı Koruma Harekâtında Yaşanan Gelişmeler 304 
UÇK'nın Sivil Bir Güce Dönüşmesi Çabası ve Sorunlar 307

NATO'ya Yönelik Eleştiriler ve Kosova'daki NATO Askerleri Komutanı General Sir Michael Jakson'a Yönelik İtaatsizlik Suçlamaları .................... 307

Kosova'nın Yeniden Yapılandırılması Toplantısı ................................... 308

Milosevic'e Karşı Muhalefet ve Sırbistan'daki Ekonomik Kriz ..................... 309

KFOR'un Varlığına Karşın Yugoslavya'da Süren Etnik Şiddet ve Meydana Gelen Önemli Gelişmeler .............................................................. 315

Kosova Konusunda Avrupa Güvenlik ve İşbirliği Teşkilat (AGIT) Raporu (6 Aralık 1999) ...................................................................... 320

2000 Yılında Yugoslavya ve Kosova'da Meydana Gelen Gelişmeler............ 324

Balkan Ülkeleri Zirvesi ............................................................ 324

Yugoslav Siyasal Sisteminde Yaşanan Gelişmeler ................................. 325

Şubat 2000'de Kosova'da Tırmanan Şiddet ve Sonuçları .......................... 328

Yugoslavya İç Siyasal Sisteminde Yaşanan Gelişmeler ............................. 331

Sırplar ve NATO Askerleri Arasındaki Çatışmalar .................................. 333

Milosevic Rejimine Karşı Büyüyen Muhalefet ve Mayıs 2000'de

Meydana Gelen Gelişmeler ............................................................ 337

Milosevic'e Karşı Yöneltilen Savaş Suçları Suçlamalarının İktidarına

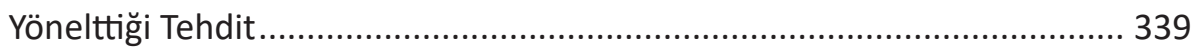

Kosova'da İlk Serbest Seçimler İçin Çağrı............................................ 340

Yugoslavya'da Başkanlık, Federal ve Yasama Meclisi Seçimleri ................. 341

Bir Devrin Sonu: Milosevic'in Devrilmesi......................................... 344

Yugoslavya'da Yeni Geçici Hükümetin Kurulması ve Yugoslavya'nın Yeniden BM Üyeliğine Kabulü.......................................................... 349

Kosova'da Artan Etnik Şiddet..................................................... 352

Sırbistan'da Yasama Seçimleri ve Meydana Gelen Gelişmeler .................. 355



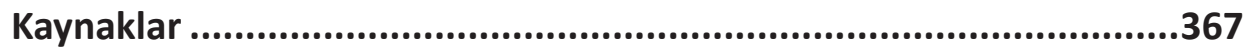

Özgeçmiş ..................................................................................379 